Artículos

\title{
El meme Jujeño en la cultura digital interactiva
}

\section{Meme Jujeño na cultura digital interativa Jujuy's memes in interactive digital culture}

\section{Vidal, Fernando}

Fernando Vidal

josfervidal@gmail.com

Facultad de Humanidades y Ciencias Sociales,

Universidad Nacional de Jujuy, Argentina

REVCOM. Revista científica de la red de carreras de

Comunicación Social

Universidad Nacional de La Plata, Argentina

ISSN: 2451-7836

Periodicidad: Bianual

núm. 13, e067, 2021

redcom.revcom@gmail.com

Recepción: 15 Junio 2021

Aprobación: 06 Septiembre 2021

URL: http://portal.amelica.org/ameli/journal/203/2032750008/ DOI: https://doi.org/10.24215/24517836e067

\section{(1) (1)}

Esta obra está bajo una Licencia Creative Commons AtribuciónNoComercial-CompartirIgual 4.0 Internacional.
Resumen: Este trabajo propone aportes teórico-metodológicos para el análisis de memes en internet publicados en páginas “jujeñas” de Facebook, entendiendo la circulación de memes como un fenómeno de la comunicación digital interactiva. En este sentido, consideramos posibles instancias de mediación del meme que implican competencias y usos posibles en su diseño y en su lectura. Esto, para finalmente proponer un abordaje que piensa Facebook como plataforma, en tanto sus posibilidades de interacción significativa.

Palabras clave: Meme, Facebook, comunicación digital interactiva, mediación.

Resumo: Este trabalho propõe contribuições teóricometodológicas para a análise dos memes da internet publicados nas páginas de "Jujuy" do Facebook, entendendo a circulação dos memes como um fenômeno da comunicação digital interativa. Nesse sentido, consideramos possíveis instâncias de mediação de memes que envolvem competências e possíveis usos em sua concepção e leitura. Isso, para finalmente propor uma abordagem que pensa Facebook como plataforma, na medida em que suas possibilidades de interação significativa.

Palavras-chave: Meme, Facebook, comunicação digital interativa, mediação.

Abstract: This work proposes a theoretical-methodological contributions for the analysis of internet memes published on "Jujuy" Facebook pages, understanding the circulation of memes as a phenomenon of interactive digital communication. In this sense, we consider possible instances of meme mediation that involve competencies and possible uses in its design and in its reading. This, to finally propose an approach that think Facebook as platform, insofar as its possibilities of meaningful interaction.

Keywords: Meme, Facebook, interactive digital communication, mediation.

\section{DES-ARMANDO UNA PROPUESTA}

En este trabajo presentamos una propuesta para el análisis de memes que circulan en internet. Para esto utilizamos publicaciones realizadas en Páginas jujeñas de Facebook. ${ }^{1}$ Esto implica, por lo menos, cuatro 
aspectos diferentes. El primero, consideramos que la producción de memes en páginas jujeñas de Facebook tiene una lógica propia que, a pesar se verse transversalizada por la convergencia digital (Martín-Barbero, 2008, p. 22), contiene competencias y sentidos específicos relacionados con la idea de jujeñidad de una página en Facebook y esto, define un proceso de producción, publicación y circulación que profundizaremos a posteriori.

En segundo lugar, entendemos que la publicación y circulación de memes en la dinámica de la comunicación digital interactiva supone la disolución de las fronteras entre productores y consumidores (Scolari, 2008, p. 240). Esto supone que la intertextualidad es un elemento fundamental para la intelección de los memes en internet. Es preciso, entonces, reflexionar los diálogos posibles entre el contexto, la página y sus filtros, la coyuntura, aspectos culturales, estéticos, etc., con el fin de percibir y disociar determinados contratos de interacción posibles (Scolari, 2008, p. 267) y/o lectores modelos (Eco, 1993, p. 72) o usuario del modelo (Scolari, 2004, p. 154).

En tercer lugar, con la idea de páginas “jujeñas" de Facebook, le asignamos no sólo a la producción, circulación y transformación de los memes publicados en Facebook sino también a las posibles lecturas de éstos una serie de competencias, que Eco (1993, p. 73), define como gramaticales. Esta propuesta conceptual, que se refiere al texto, es percibida por Scolari (2008, p. 216) desde el hipertexto, implicando un lector activo, que no sólo elige sus recorridos de lectura, sino que también tiene la oportunidad de leer como si fuera autor, esto establece nuevas formas de escritura participativa. Esto, conlleva a reflexionar sobre la existencia de un sujeto fragmentado (Zegada y Guardia, 2018, p. 58) que requiere de la presencia de otros para completarse y compactarse. Que, en el caso de Facebook, por ejemplo, se produce en la presencia de múltiples individuos aislados pero interconectados en la idea de una identidad jujeña.

Cuarta parte, precisamos reflexionar sobre las implicancias de tomar Facebook como referencia, en detrimento de otras páginas y/o redes de socialidad por plataformas (Van Dijck, 2019, p. 19) para la recolección de memes. A partir de esto, considero 4 páginas “jujeñas” de Facebook y más de 50 memes. Los que se presentan como imágenes estáticas e imágenes macro. Y el desarrollo de este artículo, si bien se presenta de manera taxativa, no será desarrollado de esta manera, sino que aquellas implicancias de la propuesta mencionadas se entrecruzan en su proceso.

\section{DE LOS MEMES A LAS MEDIACIONES}

Para el abordaje del meme de internet proponemos, es preciso aclarar que el mismo es apreciado como género, en tanto sus lógicas de producción y sus lógicas de uso (Martín-Barbero, 1987, p. 241). En este sentido, entendemos que el género no es algo que le pase al texto o al hipertexto. Sino algo que pasa por el texto o el hipertexto, por el meme. Es decir, es una cuestión de competencias, una estrategia de comunicabilidad que se presenta en su formato. Dice, en este aspecto, Martín-Barbero que los géneros no son abordables en términos de semántica o de sintaxis, que exigen la construcción de una pragmática que dé cuenta cómo opera su reconocimiento de determinada comunidad cultural. (p. 242)

Bajtín (2013, p. 245) sugiere que los géneros son diversos y están estrechamente relacionados con la actividad humana, por lo que son inagotables en su praxis. Esta premisa, nos permite pensar al meme como género de la comunicación digital participativa (Wiggins, 2016, p. 470) o de internet que se inscribe en lo que Martín-Barbero denomina el habla social ampliada (2017, p. 17) en la que la centralidad de la palabra es arrebatada a los medios hegemónicos y las fuentes de información clásicas para ocupar "territorialidades digitales, mezcladores de narrativas y dispositivos, y fans de múltiples relatos a la vez. Una experiencia novedosa de disfrute y juego: una fiesta transmedial" como dice Jenkins (2008), como se citó en Amado y Rincón (2017, p. 189).

La propuesta de meme como género nos resulta fundamental en la intelección de aquellas dinámicas culturales que tienen lugar en las narrativas digitales propias de la comunicación participativa. Ya que, en este 
sentido, cómo género de la comunicación digital participativa, el meme de internet no es una simple imagen estática con texto, sino que representa "actividades que guían y alteran las dinámicas de la cultura. En este sentido, el meme... es un complejo sistema de motivaciones sociales y actividades culturales que resultan de la comunicación y el ímpetu de esa comunicación”2 (Wiggins, 2017, p. 3).

Como género podemos distinguir, a priori, en el meme de internet al humor como elemento indisociable de su constitución y un recurso determinante en su construcción discursiva. Y en tanto expresión semiótica (Magariños de Morentin, 2008, p. 40) se significa en función de un grupo social, una idiosincrasia, una temática y un contexto espaciotemporal y social específicos.

El humor, en el meme, puede generar hostilidad o solidaridad (Carniel, Ruggi \& Ruggi, 2018, p. 526) debido a que se inscribe en diferentes posicionamientos, que son principalmente políticos. El chiste político no sólo cumple el rol de burlar lo establecido, o al poder imperante en periodos autoritarios como aseguran Zegada Claure y Guardia Crespo (2018, p. 390), sino que también, puede favorecer al mantenimiento de las relaciones de poder.

Es ineludible mencionar que el humor surge siempre de un preconcepto (Carniel, Ruggi \& Ruggi, 2018) que se construye en esa cultura digital participativa como un relato que puede divergir en múltiples subjetividades, generando un espacio de múltiples inteligencias (Zegada Claure \& Guardia Crespo, 2018) donde se conectan diferentes sensibilidades en función de una idea y sin necesidad de conocerse físicamente. Estas características que hacen al humor memético suponen que ni la fuente, ni el relato, ni la conclusión del chiste deben ser irrefutables. Seguramente es proclive a ser cuestionable, lo que habilita el análisis ulterior.

En este aspecto, es Todorov (2012), quien menciona las fuentes posibles del chiste, como género discursivo: En suma, engañar la expectativa de los auditores (usuarios-consumidores), burlarse de los defectos de sus semejantes, mofarse - de ser necesario- de los suyos propios, recurrir a la caricatura o la ironía, lanzar ingenuidades fingidas, señalar la necedad del adversario (p. 390). La producción, publicación y circulación de memes en tanto géneros supone una constante transformación discursiva, en tanto búsqueda e interacción con lectores posibles que compartan, comenten y reaccionen a esos memes de internet que se publican en Facebook, por los que consideramos para este trabajo.

\section{Facebook: ¿donde se inscriben los memes?}

Pensamos en Facebook como espacio virtual de donde recolectar los memes en función de algunas cuestiones como la cantidad de usuarios/as. Por ejemplo, los datos obtenidos The Global State of Digital, ${ }^{3}$ en el año 2019, Facebook ocupó el segundo lugar considerando las redes sociales virtuales con más usuarios en Argentina, dejando el primer lugar a YouTube y el tercer puesto a WhatsApp, otra plataforma donde suelen compartirse asiduamente memes. Ya en julio de 2020 Facebook alcanzó a ocupar el primer lugar entre las redes sociales más utilizadas por argentinos y argentinas, con un total de 23 millones de usuarios/as, de acuerdo con el artículo publicado en Digital House. ${ }^{4}$

Desde una mirada en la plataforma: Facebook, allá por el 2005, comenzó a convertirse en un periódico personalizado (Parisier, 2017, p. 45) donde las noticias eran generadas por lxs usuarixs. Las publicaciones se presentan en función de una "línea de tiempo" (Van Dijk, 2019, p. 91) que conforma una base de datos de usuarixs, para usuarixs. El orden y la importancia de estas noticias-publicaciones no responde, sin embargo, a una disposición del/la usuario/a, sino a una serie de algoritmos que buscan mantener la atención de los/ as usuarios/as durante una mayor cantidad de tiempo (Zuazo, 2018, p. 101). Cuestión que este trabajo no profundiza. Aunque se cree preminente visibilizar estas características.

La idea de periódico personalizado, podemos asociarla a la del weblog o blog (Scolari, 2008, p. 195-1969), que es un sitio que periódicamente es actualizado donde se recopilan cronológicamente textos, hipertextos y/o artículos con usos o temáticas específicas. Podríamos reconocer una página “jujeña” de Facebook como 
un espacio que tiene a priori un lector modelo cuya principal competencia es ser jujeño, y transitar en su cotidianidad la realidad sociopolítica y cultural de nuestra provincia. En el caso de la comunicación digital interactiva, Carlos Scolari (2008, p. 88) toma, el concepto de modelo conceptual del usuario que se desarrolla, precisamente, en función de la interacción de usuario con el sistema.

Facebook se caracteriza por ser una página en constante transformación, mutatis mutandis, como afirman López y Ciuffoli (2012) no sólo con el objeto de mantenerse vigente. Facebook, si bien mantiene una arquitectura uniforme en tanto colores y en algunos aspectos de su interfaz, constantemente se modifica con el fin de contener en mayor medida otras páginas y transformarse en una suerte de sistema operativo de redes sociales. Facebook permite la interacción con otras redes como YouTube, pero también con plataformas virtuales de un entrono específico, diarios digitales locales (jujeños) por ejemplo.

Crear un entorno, una página dentro de Facebook con contenidos referidos a cuestiones culturales, políticas y/o sociales de una región determinada es posible por la interfaz que propone su arquitectura. Esto nos permite hacernos a la idea de una página “jujeña”, en tanto contenidos y diálogos posibles en Facebook de manera más clara que en otras redes sociales virtuales.

\section{El CaSo de laS PÁginas “JuJEÑas” DE MEMES}

Consideramos una muestra de alrededor de 50 memes publicados entre enero y febrero del 2021 en 4 páginas “jujeñas” de Facebook. Las páginas de Facebook por utilizar son:

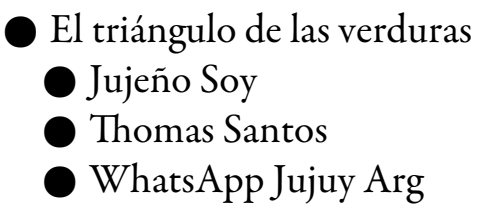

Las páginas seleccionadas abordan temáticas relacionadas a aspectos socio-políticos y culturales de Jujuy. No se consideró que todas sean las que tienen más seguidores o "me gusta", lo que nos interesa es el tipo de contenido. Memes que hacen referencia a temas que hacen a la jujeñidad. Ese contenido define, en términos generales, la calidad de “jujeña” de una página o de un meme.

\section{Un abordaje sociosemiótico del meme}

Para el abordaje que proponemos, tomamos la sociosemiótica que Fernández (2018, pp 46-47) utiliza para el análisis de plataformas considerando los sistemas de intercambio discursivo desde tres instancias diferentes: una semio-histórica, un estado sociosemiótico y el análisis del discurso.

Los memes seleccionados serán abordados desde una semiótica multimodal (Venier, 2020, pp 29-30) entendiendo al "modo" como un sistema semiótico convencionalmente reconocido con una gramaticalidad interna, como el texto, color, o el diseño de las imágenes. Para esto, se prefigura la utilización y adaptación no dogmática (González Pérez, 2019, p. 66) de las operaciones semióticas de Magariños.

Por un lado, la semiótica Icónica aplicada al meme identificando diferentes atractores mnemónicamente disponibles (Magariños de Morentin, 2008, p. 198) que se actualizan mediante la propuesta hipertextual en asociación.

Los memes están destinados a configurar atractores existenciales (principalmente), debido a que se trata, no solamente, pero si de manera dominante, de discursos conformados por imágenes que poseen una analogía con un existente, por lo que se puede hablar de "sinsignos icónicos" (CP 2.245). Esos atractores existenciales se configurarán (o actualizarán) de acuerdo a las "componentes dinámicas que posea almacenadas en su memoria visual" (Magariños, 2008:224) la persona que los interpreta. (González Pérez, 2019, p 66) 
Por otra parte, para el análisis del texto, también retomaremos la propuesta de Magariños de Morentin (2008), con el fin de determinar las definiciones contextuales que cumplen la función de actuar como ejes conceptuales ordenadores, según los cuales pueden agruparse las definiciones obtenidas. Los conjuntos asi constituidos son representativos de los distintos modos de atribuir significado a los correspondientes términos, por parte de la comunidad o sector social que produjo los discursos en estudio (p. 146).

Expondremos esto, a continuación, desde una clasificación general de memes publicados en estas páginas jujeñas de Facebook. Esta clasificación surge de esas operaciones semióticas, considerando el enfoque de plataformas que propone Fernández.

Ya que la relación plataforma-contenido, si se tiene en cuenta la uniformidad arquitectónica de Facebook, es fundamental. Porque aunque no sólo las temáticas propias de los memes definen a la página, sino todo tipo de publicaciones y el uso de la interfaz por parte de los/as administradores, se puede señalar que son los memes una parte importante en la definición identitaria de la plataforma dentro de la virtualidad.

\section{Jujeños en El triángulo de las verduras}

El triángulo de las verduras 5 es una página creada el 20 de enero de 2017, con 148.860 seguidores (foto de portada Cerro de 7 colores) al 15 de febrero de 2018. Se caracteriza como un Sitio web de entretenimiento, según su descripción. Podemos clasificar aquí la producción de memes de la siguiente manera:

1. Meme foto: es la foto de una determinada circunstancia que (dentro de la imagen no tiene texto escrito) pero que está siempre acompañado de un comentario, que denominaremos, expositor que le da sentido al meme. La foto se caracteriza por no presentar ningún personaje o famoso conocida de los medios masivos o de las redes sociales.

2. Meme TV: tiene como característica estar conformado por situaciones que se presentan con diferentes personajes de la pantalla chica, ya sean series o películas (que pasen por TV), argentina o extranjera (generalmente yanquis), etc. Estos memes dialogan con situaciones de la TV y pueden no contener texto.

3. Meme Simpson: este tipo de memes se presenta como una subclase de la categoría anterior. Pero que toma forma en el diseño con escenarios Simpson, un programa con entidad propia en tanto audiencias e inteligibilidad, y que es un recurso estilístico de muchas páginas jujeñas. Se presentan una situación particular con personajes de los Simpson, modificados o no, en función del mensaje. Este recurso tiene mucha llegada en el público que consume páginas de memes jujeñas.

4. Meme en viñetas: este formato se presenta como un recurso para dividir secuencias temporales, para contrastar formas "jujeñas" o típicas de Jujuy con otras formas, algo que gusta o que no gusta, etc. 


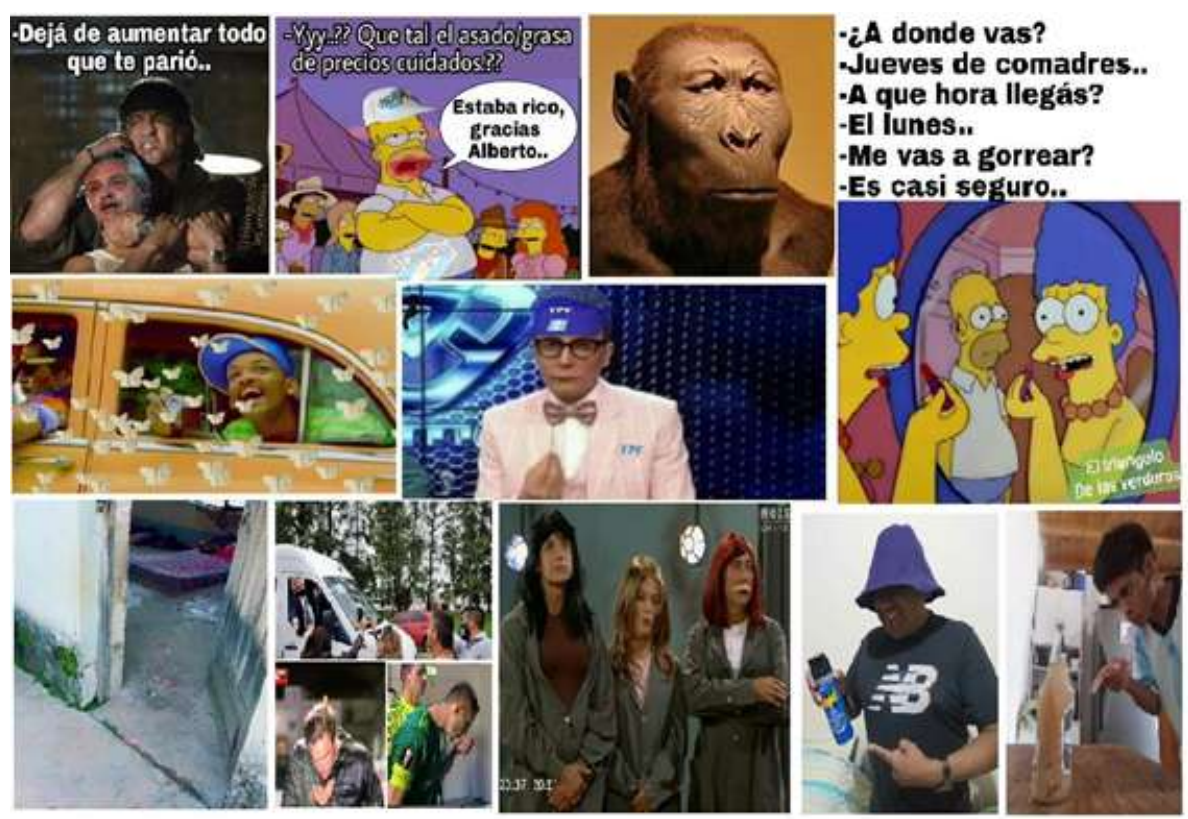

IMAGEN 1.

Selección de memes publicados en la página "El triángulo de las verduras" Fuente: elaboración propia

La clasificación de memes es funcional y la producción de los mismos puede transitar intersecciones entre las diferentes propuestas.

En relación a las temáticas podemos considerar aquí tres grandes líneas: Memes de Identidad y prácticas culturales, memes políticos y memes de la vida cotidiana. Estas temáticas generales serán desarrolladas en cada página, en El triángulo de las verduras por una parte podemos encontrar memes dentro de estas 3 categorías generales:

En la categoría Memes de identidad y prácticas culturales, podemos observar temas que distinguen situaciones cotidianas, costumbres y prácticas culturales jujeñas. Como aquellos memes que hacen referencia a los festejos del Carnaval y al alcoholismo, nuestra reacción ante la aparición de los pirpintos, ${ }^{6}$ el festejo del jueves de comadre, etc.

En los memes político: aparece la mirada crítica-política principalmente al Gobierno nacional. Estos memes apuntan a los actuales aumentos de precios, en general, al aumento de nafta, a la posibilidad de hacer un asado, de esta forma también critican a los militantes del Partido Justicialista y sus divergencias, como la Cámpora.

Los memes de la vida cotidiana: suponen problemáticas relacionadas a las relaciones socioafectivas: amor, amistad, etc., relaciones políticas familiares como con "la suegra", cuestiones relacionadas a efemérides o a la distinción social de una determinada clase. Este último criterio temático incluye un meme, donde por ejemplo se observa una puerta de chapa abierta que deja ver un colchón tirado en el piso y una forma de vida precarizada, esta imagen es acompañada de un comentario que dice "La elegancia del Bryan".

\section{Como cuando, Jujeño soy}

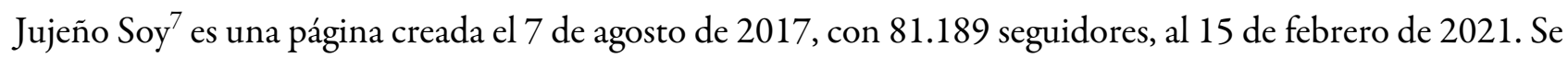
caracteriza como un Sitio web de entretenimiento. Esta página se caracteriza por utilizar principalmente los elementos identitarios en su haber. 
Para no repetir clasificaciones, no mencionaremos aquellas que se repitan, y describiremos sólo aquellos formatos que aparezcan por primera vez. Conforme al diseño de los memes podemos encontrar modo viñetas, memes Simpson, foto TV y otros dos formatos:

- Meme cartel: Que utiliza un cartel con características de publicidad y le asigna, mediante el texto sentidos en el humor relacionados a la publicación de memes.

- Plantilla de meme: Alude a la utilización de formatos de memes que se diseñan a partir de modelos que circulan de forma global en las redes sociales o el internet en general, tomando forma "jujeña” a partir de modificar algún aspecto, texto o imagen que le otorgue este sentido.

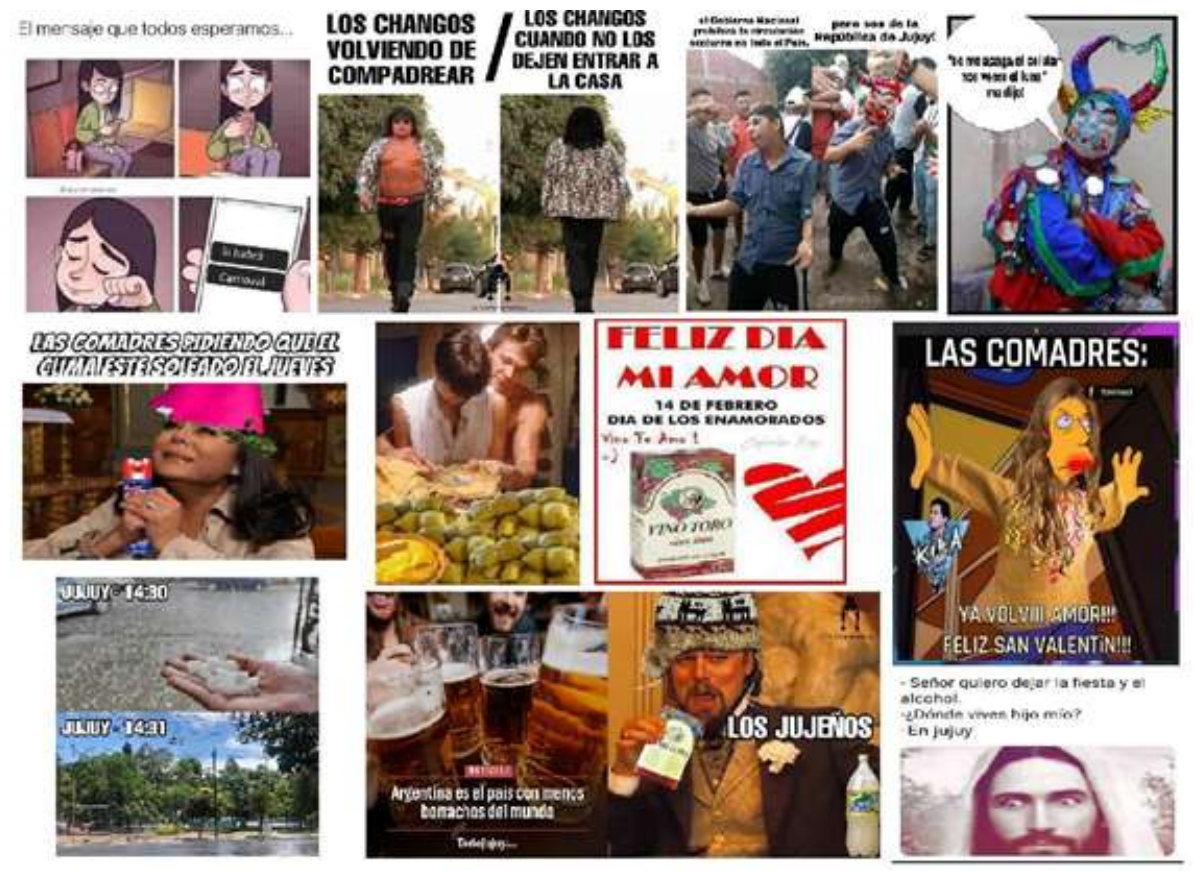

IMAGEN 2

Selección de memes publicados en la página “Jujeño soy” entre enero y febrero de 2021

Fuente: elaboración propia

En cuanto a la temática observada podemos distinguir diferentes aspectos relacionados a la categoría Identidad y prácticas culturales: el carnaval, San Valentín en Jujuy, el alcoholismo, la infidelidad, pero también y agregado como un ad hoc en esta categoría las condiciones climáticas de la provincia, que podríamos pensar como aspectos relacionados a vivir en nuestra provincia que no son sociales, pero que sí infieren en ciertas prácticas como la vestimenta o la circulación en la provincia.

\section{Es línea con Thomas Santos}

Thomas Santos ${ }^{8}$ es una página creada el 4 de marzo de $2020^{9}$ con 2289 seguidores al 15 de febrero de $2021 .^{10}$ En su Información figura este cartel: Hacemos humor. También se repara calzado. Si bien Thomas Santos es la página con menos seguidores de las que tomamos como referencia, es por otro lado en cuanto al diseño de los memes, la más controversial, simple y creativa.

Thomas Santos, es una página que surge del Perfil de Facebook Thomas Santos, que utilizaba un programa radial llamado Todos Santos, hasta el año 2019. Este programa se trasmitió por la Voz del Cerro, una radio comunitaria de la cual existen diferentes trabajos de investigación en Jujuy. La temática del programa radial, que heredaron posteriormente los memes y otras producciones audiovisuales es de humor político. 
Thomas Santos toma varios de los formatos anteriormente mencionados, pero publica en general en 2 formatos sus posteos. El primero un formato de sólo texto en forma de carteles, con mensajes irónicos, o planteos políticos, este formato lo caracterizamos como Imagen Macro, y el formato característico de Thomas Santos es:

- Meme noticia: En este formato el diseño rompe con dos lógicas de la producción de memes. Por un lado, la utilización de texto, que en este tipo de memes es mayor que en uno convencional y, por otra parte, la tipografía de memes, que normalmente contienen fuentes sanserif como Impact, por ejemplo, para usar tipografías de otras familias como las Romanas, por ejemplo, Times New Roman. El meme noticia se publica como la portada de una nota de diarios digitales (con su título, bajada, foto). Al publicarse inicialmente con formatos correspondientes a Diarios digitales Jujeños, esas publicaciones fueron tomadas por otras páginas como FakeNews que luego las denunciaron como tales. Actualmente, los autores de la página optan por continuar el formato Meme noticia sin poner la marca de medios digitales jujeños.

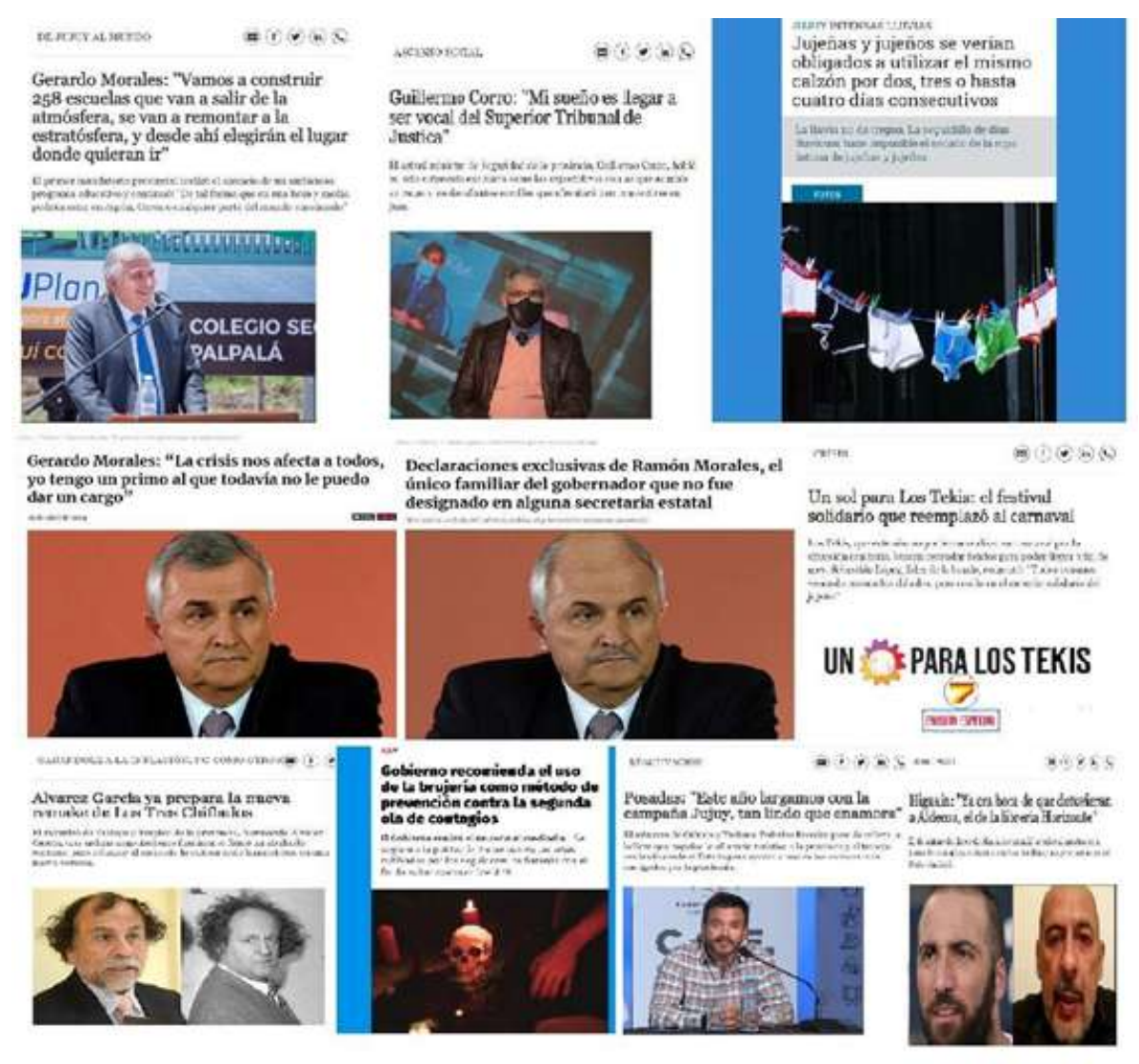

IMAGEN 3.

Selección de memes publicados en la página "Thomas Santos”

Fuente: elaboración propia

La mayor parte de la estructura temática de Thomas Santos pasa por ser memes políticos, que toman el discurso político gubernamental y lo trasladan a la lógica del meme en un formato de discurso periodístico, que también es político. Podríamos leer, entre los memes de Thomas Santos, tal vez una "línea editorial" más clara que con otras páginas. También se toman otros aspectos, pero en general se mezclan con la temática política. Es menester aclarar que las temáticas tampoco son taxativas, pueden mezclarse, articularse y transformar los sentidos que vemos y leemos en los memes, de manera que podamos identificarnos de manera más concreta y compartamos, circulemos y le demos tránsito en esa vida fugaz que tienen. Entre mayor diálogo con diferentes aspectos de una identidad contienen en su discurso, más tiempo sobreviven 
en la dinámica de la comunicación digital interactiva. La vida del meme es proporcional a su grado de intertextualidad.

\section{¿Qué pasa con WhatsApp Jujuy?}

WhatsApp Jujuy Arg es una página creada el 15 de octubre de 2014, con 402875 seguidores al 15 de febrero de 2021. Se caracteriza como una Comunidad, es menester plantear que existen por lo menos tres páginas con la misma denominación, por lo que la página ésta página se jacta de ser Página Oficial All rights reserved.

WhatsApp Jujuy Arg (WJA) es la página con mayor cantidad de seguidores, y contiene todos los diseños anteriormente mencionados, menos el Meme noticia. Podemos agregar al listado de estilos/diseños una nueva:

- Plantilla de meme-caricatura: este meme toma una caricatura no reconocida por sus personajes, pero que representa una situación o hecho que podemos comprender automáticamente por la disposición de la imagen. Es el caso del meme que hace referencia a Telegram, donde se ve que dos hombres vestidos con poleras oscuras, como mormones tocan a la puerta de una persona y se proponen a hablar de Telegram. Esta práctica social podemos relacionarla con los mormones o testigos de Jehová.

Por otra parte, si bien, también considera los tres ejes temáticos la propuesta de WJA es la más acorde a temáticas masivas y “argentinas” como podemos observar en las imágenes que vemos en la 4 propuesta.

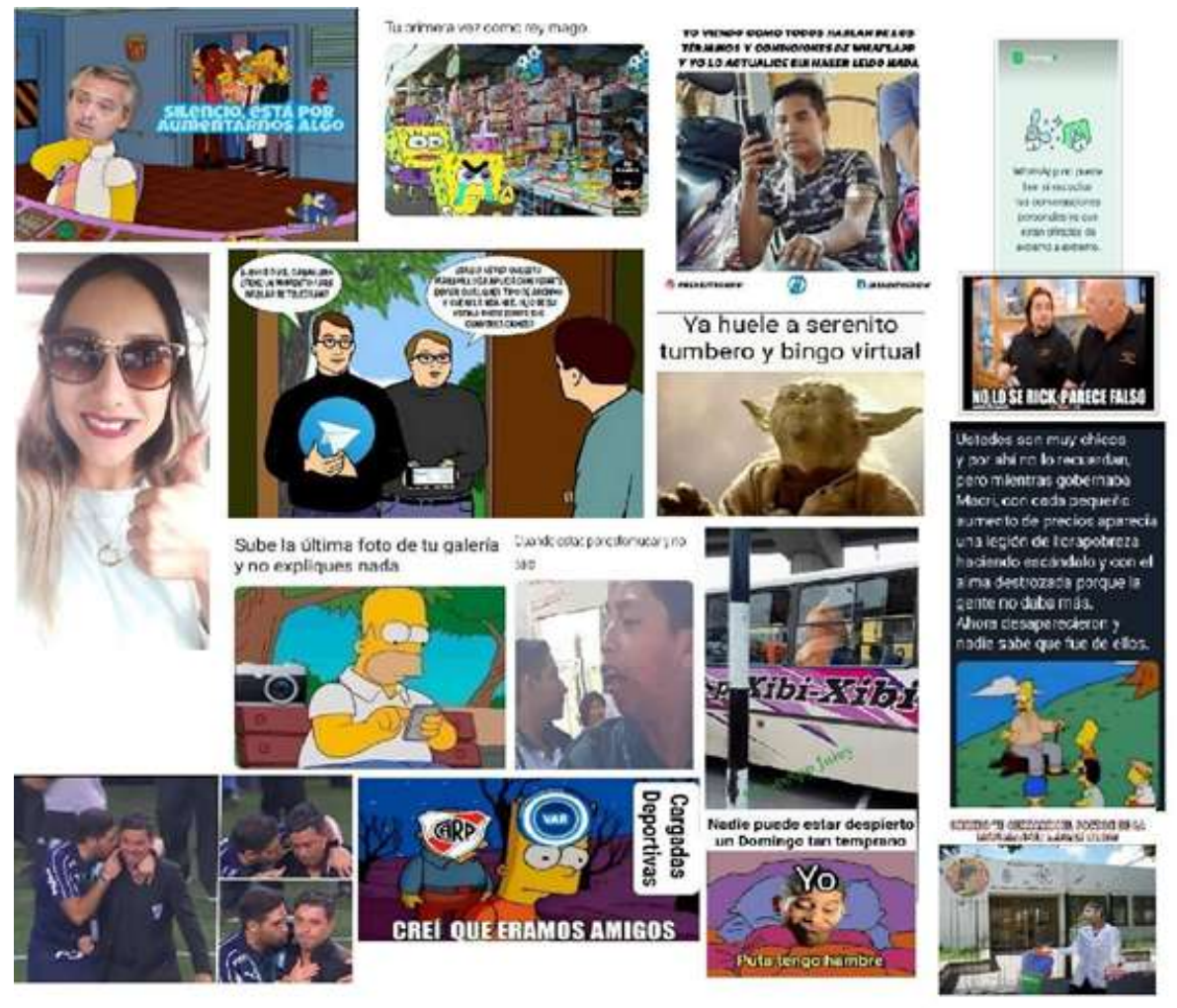

IMAGEN 4.

Selección de memes publicados en la página "WhatsApp Jujuy Arg” Fuente: elaboración propia

Los memes de WJA en general apuntan a situaciones o acontecimientos sociales a nivel nacional, aunque a veces van por lo local también, como cuando muestran imágenes de mujeres coqueando, o hablan de San Valentín mostrando un oso gigante que viaja en su propio asiento en un colectivo de la empresa Xibi-Xibi. ${ }^{11}$ 
WJA es posiblemente la página donde los memes se producen, comparten, circulan y transforman en mayor medida, esto debido a que las temáticas que aborda son muy variadas, dentro de los tres ejes temáticos que planteamos, pero también, si se quiere, en un eje temático que tiene todo para configurarse a partir de su propia existencia, el que hace referencia al futbol.

Los memes que aparecen en WJA proponen temas relacionados a política, deportes, efemérides, costumbres, etc.; y reproducen mensajes que podemos escuchar en radio o TV asiduamente. Esto, podemos conjeturar que, es uno de los motivos por lo que es una las páginas con mayor seguidores jujeños/as. Ya que los/as usuarios/as modelos que transitan y circulan memes en esta página pueden encontrar múltiples referencias a prácticas de orden social y simbólico que hacen a la jujeñidad.

\section{Cuadro general y conclusiones}

A continuación ponemos en blanco la clasificación realizada tanto en el estilo y diseño como en las temáticas abordadas por memes jujeños (Cuadro 1).

\section{CUADRO 1.}

\begin{tabular}{|c|c|c|c|}
\hline \multicolumn{4}{|c|}{ ños } \\
\hline $\begin{array}{l}\text { Meme } \\
\text { foto }\end{array}$ & $\begin{array}{l}\text { Meme } \\
\text { TV }\end{array}$ & $\begin{array}{l}\text { Meme } \\
\text { Simpson }\end{array}$ & Meme viñeta \\
\hline Cartel & $\begin{array}{l}\text { Plantilla } \\
\text { de } \\
\text { meme }\end{array}$ & $\begin{array}{l}\text { Meme } \\
\text { noticia }\end{array}$ & $\begin{array}{l}\text { Plantilla de } \\
\text { meme-caricatura }\end{array}$ \\
\hline \multicolumn{4}{|c|}{ Temáticas de memes jujeños } \\
\hline $\begin{array}{l}\text { Identidad } \\
\text { o } \\
\text { prácticas } \\
\text { culturales }\end{array}$ & $\begin{array}{l}\text { Meme } \\
\text { político }\end{array}$ & $\begin{array}{l}\text { Vida } \\
\text { cotidiana }\end{array}$ & Futbol \\
\hline
\end{tabular}

Estilo, diseño y temáticas de los memes jujeños analizados Fuente: elaboración propia

Es preciso hacer referencia a que estas categorías no se excluyen, por el contrario muchas veces se encuentran en la construcción del contenido.

Podríamos afirmar sin miedo que el abordaje de memes de internet puede plantearse desde muchas otras aristas. Por ejemplo, aquellas asociadas a la Economía política de las comunicaciones, con una dirección cuantitativa asociada a una mirada sociológica a partir del manejo de datos. No obstante, consideramos que este aporte puede ser útil para mirar la publicación y circulación de memes de internet desde una mirada local, culturalmente identificada, con la posibilidad de encontrar en la socio-semiótica discursos, identidades y prácticas culturales que dialogan con estos discursos propios de la comunicación digital interactiva.

Pensamos que el meme como género, por otra parte nos permite mirar y visibilizar diferentes aspectos de la interacción en redes que hacen a la construcción de una identidad virtualizada. Aquí podemos distinguir, más allá de esos filtros de los que habla Pariser (2017), la presencia de grupos sociales, regionales, nacionales y/o provinciales en Facebook, en el marco de la ubicuidad.

La premisa de modelos de usuarios, de lectores de estas publicaciones supone pautas de contenidos que cada espacio virtual deber respetar. Los seguidores de cada página de Facebook comparten, comentan y reaccionan a determinada línea de contenidos. Esto nos permite notar que dichas lecturas responden a aquella intertextualidad que en términos generales podríamos decir que dialoga con aspectos cognitivos precedentes; pero específicamente hacer mención a cuestiones como la filiación ya sea por diferentes cuestiones como la condición etaria o nociones como la raza, la perspectiva de género ${ }^{12}$ o la clase. 
El diálogo se nos presenta como un elemento infinito en sus posibilidades. El meme dialoga aparentemente con más enunciados de los que podemos predecir en un análisis porque para cada usuario/a puede leer un meme y su sentido práctico desde diferentes aristas. Nosotros podemos intentar enfocar una propuesta. Un meme tendrá tantas lecturas como compartidos, reacciones o comentarios pueda albergar en su efímera vida en la red.

\section{REFERENCIAS}

Amado, A. y Rincón, O. (2017). La comunicación en mutación. Colombia, Bogotá: FES Comunicación.

Bajtín, M. (2013). Estética de la creación verbal. Ciudad Autónoma de Buenos Aires, Argentina: Siglo XXI.

Bischetti, L., Canal, P. y Bambini, V. (2020). Funny but aversive: A large-scale survey on the emotional response to Covid-19 bumor in the Italian population during the lockdown. (Preprint). https://doi.org/10.31234/osf.io/ef $\mathrm{k} 93$

Carniel, F., Ruggi, L.y Ruggi, J. d. (2018). Gênero e humor nas redes sociais: a campanha contra Dilma Rousseff no Brasil. Opinäo Pública, 24(3), 523-546. Disponível em https://periodicos.sbu.unicamp.br/ojs/index.php/op/a rticle/view/8654293

Eco, U. (1993) Lector in fabula. La cooperación interpretativa en el texto narrativo. Barcelona, España: Lumen.

Freire, F. (2016). Uma breve reflexäo sobre memes políticos, humor e conversacäo cotidiana informal. Em Debate: periódico de opinião pública e conjuntura política, 8(6), 34-40. Disponível em http://bibliotecadigital.tse.jus.br/ xmlui/handle/bdtse/3264

González Pérez, C. F. (2019). Memes y lenguaje inclusivo: transformaciones y resistencias. Revista Latinoamericana de Ciencias de la Comunicación, 16(30), 60-73. Recuperado de http://revista.pubalaic.org/index.php/alaic/art icle/view/1405

Fernández, J. (2018). Plataformas mediáticas: elementos de análisis y diseño de nuevas experiencias. Ciudad Autónoma de Buenos Aires, Argentina: La Crujía Ediciones.

López, G. y Ciuffoli, C. (2012). Facebook es el mensaje: oralidad, escritura y después. Ciudad Autónoma de Buenos Aires, Argentina: La Crujía Ediciones.

Magariños de Morentin, J. (2008). La semiótica de los bordes. Apuntes de metodología semiótica. Córdoba, Córdoba: Comunic-Arte.

Martín-Barbero, J. (1991). De los medios a las mediaciones. Comunicación, cultura y hegemonia. Ciudad de México, México: G. Gili.

Martín-Barbero, J. (2008). Diversidad cultural y convergencia digital. I/C Revista cientifica de información y comunicación, (5), 12-55. Recuperado de https://icjournal-ojs.org/index.php/IC-Journal/article/view/265

Martín-Barbero, J. (2017). Hacia el habla social ampliada. En A. Amado y O. Rincón, La comunicación en mutación (pp. 13-17). Colombia, Bogotá: FES Comunicación.

Pariser, E. (2017). El filtro burbuja. Cómo la red decide lo que leemos y lo que pensamos. Barcelona, España: Penguin Random House.

Scolari, C. (2004). Hacer click. Hacia una sociosemiótica de las interacciones digitales. Barcelona, España: Gedisa.

Scolari, C. (2008). Hipermediaciones. Elementos para una Teoría de la comunicación digital interactiva. Barcelona, España: Gedisa.

Todorov, T. (2012). Los géneros del discurso. Ciudad Autónoma de Buenos Aires, Argentina: Waldhuter Editores.

Van Dijck, J. (2019). La cultura de la conectividad. Una historia crítica de las redes sociales. Ciudad Autónoma de Buenos Aires, Argentina: Siglo XXI.

Venier, E. (2020). Los memes y la imitación en la socialidad tecnificada. Viator, (6), 22-47. Recuperado de http://rev ista.fhycs.unju.edu.ar/revistaviator/index.php/viator/article/view/64 
Wiggins, B. (2016). Crimea River: Directionality in Memes from the Russia-Ukraine Conflict. International Journal of Communication, (10), 451-485. Available at https://ijoc.org/index.php/ijoc/article/view/4103

Wiggins, B. (2017). Digital Dispatches from the 2016 US Election: Popular Culture Intertextuality and Media Power. International Journal of Media \& Cultural Politics, 13(1-2), 197-205. https://doi.org/10.1386/macp.13.1-2.1 $97+7$

Zegada Claure, M. y Guardia Crespo, M. (2018). La vida politica del meme. Interacciones digitales en Facebook en una coyuntura critica. La Paz, Bolivia: Plural Editores.

Zuazo, N. (2018). Los dueños de internet. Como nos dominan los gigantes de la tecnología y qué hacer para cambiarlo. Ciudad Autónoma de Buenos Aires, Argentina: Debate.

\section{Notas}

1 La idea de página “jujeña” de Facebook se encierra entre comillas, debido a que consideramos que para entender dentro de la lógica virtual de las redes como local algo que no tiene presencia física, debemos realizar una serie de descripciones, o formas de apropiación que le asignen el carácter de “jujeño”.

2 La traducción es nuestra.

3 Redes sociales más usadas en el mundo hispano: estadísticas y tácticas (hootsuite.com)

4 Las redes sociales más elegidas por los argentinos | Digital House

5 https://facebook.com/triangulode

6 Los pirpintos son mariposas de color blanco que aparecen en la región del NOA.

7 https://facebook.com/Juje\%C3\%B1o-Soy-159115951312116

8 https://facebook.com/thomas.santos.ok

9 Es menester aclarar que antes Thomas Santos anteriormente presentaba la interface de un perfil, no de una página.

10 Esta página dejó de existir el 7 de abril del 2021, dejando dos páginas: Guido Santos y Jujuyflix

11 Xibi-Xibi es una empresa de transporte público jujeña, la misma cuenta con una flota de colectivos que transitan diferentes barrios de San Salvador de Jujuy.

12 Aquí se hace referencia a la perspectiva de género, como identidad y preferencia sexual, no en el sentido en el que hemos venido trabajando en el artículo. 